\title{
Venous Thromboembolism Secondary to Adult-Onset Still's Disease: a Case Report
}

\author{
Veronica Calborean $^{1}$, Victor Gheorman ${ }^{2}$, Cristian Constantin ${ }^{3}$, Octavian Istrătoaie ${ }^{1}$ \\ ${ }^{1}$ Department of Cardiology, University of Medicine and Pharmacy, County Hospital, Craiova, Romania \\ ${ }^{2}$ Department of Psychiatry, University of Medicine and Pharmacy, Neuropsychiatry Hospital, Craiova, Romania \\ ${ }^{3}$ Department of Radiology, University of Medicine and Pharmacy, County Hospital, Craiova, Romania
}

\section{ABSTRACT}

A 56-year-old man presented to the emergency department with pain, swelling, and restricted mobility of the left lower limb and shortness of breath on exertion in the previous 3 days. Seven months prior to this presentation, he had been diagnosed with adult-onset Still's disease based on the Yamuguchi criteria, after excluding the presence of any other disease. The patient had been treated with prednisolone and methotrexate. Subsequent investigations revealed that he developed bilateral deep venous thrombosis and bilateral pulmonary emboli. This case emphasizes that adult-onset Still's disease can be a rare but life-threatening cause of venous thromboembolism.

Keywords: adult-onset Still's disease, deep venous thrombosis, pulmonary emboli

\section{ARTICLE HISTORY}

Received: April 28, 2018

Accepted: May 30, 2018

\section{CORRESPONDENCE}

\section{Victor Gheorman}

Str. Spania nr. 32

200505 Craiova, Romania

Tel: +40 768033526

E-mail: gheormanv@gmail.com

\section{INTRODUCTION}

Adult-onset Still's disease (AOSD) is considered a complex autoinflammatory syndrome of unknown cause. ${ }^{1}$ AOSD is a rare multisystemic disease, with an estimated prevalence of under 1 case per 100,000 subjects. ${ }^{2}$

This syndrome was described in 1897 by George Frederic Still as a chronic joint disease which appears in childhood. ${ }^{3}$ After 70 years, in 1967, the existence of the adult form of the syndrome was acknowledged. $4^{4}$ The clinical picture in an AOSD patient is characterized by fever (above $39^{\circ} \mathrm{C}$ ), arthralgia, sore throat, and rash. ${ }^{5}$ Other features, representative for this rare condition, are lymphadenopathy, hepatosplenomegaly, pleurisy, pericarditis, and involvement of the central nervous system. ${ }^{6,7}$ The diagnosis of
AOSD is currently established based on Yamaguchi's criteria (Table 1), according to which the diagnosis requires the presence of at least five criteria, out of which at least two major. ${ }^{8}$

Pulmonary embolism (PE) is a major cardiovascular emergency, associated with a mortality rate of approximately $30 \% .{ }^{9}$ Nowadays, anticoagulant therapy is considered the mainstay of medical therapy, decreasing the mortality associated to this major emergency to $2-8 \% .^{10}$ Therefore, a quick and accurate diagnosis of this condition could be vital to allow the prompt initiation of effective therapy. ${ }^{11}$

In this case report we aim to demonstrate how deep vein thrombosis (DVT) and a consequent PE can represent a potential complication of AOSD. 
TABLE 1. Diagnostic criteria for adult-onset Still's disease ${ }^{7}$

\begin{tabular}{lll}
\hline MAJOR CRITERIA & MINOR CRITERIA & EXCLUSION CRITERIA \\
\hline $\begin{array}{l}\text { Fever }>39^{\circ} \mathrm{C} \text {, lasting 1 week or longer } \\
\begin{array}{l}\text { Arthralgia or arthritis, lasting 2 weeks } \\
\text { or longer }\end{array}\end{array}$ & $\begin{array}{l}\text { Sore throat } \\
\text { Recent development of significant } \\
\text { Typical salmon-colored rash }\end{array}$ & $\begin{array}{l}\text { Infections } \\
\text { Hepatignancies (malignant lymphoma) }\end{array}$ \\
$\begin{array}{l}\text { Leukocytosis }>10.000 / \mathrm{mm}^{3} \text { with }>80 \\
\text { polymorphonuclear cells }\end{array}$ & Abnormal liver function tests & $\begin{array}{l}\text { Other rheumatic disease (systemic } \\
\text { vasculitides) }\end{array}$ \\
& $\begin{array}{l}\text { Negative tests for antinuclear antibody } \\
\text { (IF) and rheumatoid factor (IgM) }\end{array}$ & \\
\hline
\end{tabular}

\section{CASE PRESENTATION}

We report the case of a 56-year-old Caucasian man who was referred to the hospital after presenting with pain, edema, and restricted mobility of the left lower limb and shortness of breath on exertion in the last 3 days. The initial examination of the patient revealed a mildly elevated arterial pressure (142/88 mmHg) and a peripheral oxygen saturation of $97 \%$. Physical examination showed the presence of painful edema of the left leg. Laboratory tests revealed a hemoglobin level of $11.9 \mathrm{~g} / \mathrm{dL}$, elevated levels of C-reactive protein (19.7

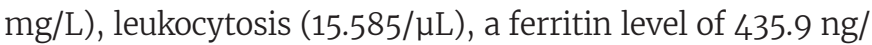
$\mathrm{mL}$, an erythrocyte sedimentation rate of $37 \mathrm{~mm} / 1 \mathrm{st} \mathrm{h}$, and a D-Dimer concentration of $>5 \mathrm{ug} / \mathrm{mL}$. Abdominal examination showed mild hepatosplenomegaly. Transthoracic echocardiogram revealed mild mitral and aortic valve regurgitation, without any vegetations or pericardial effusion.

Deep vein thrombosis (DVT) was suspected based on the patient's symptoms and elevated levels of D-dimers.

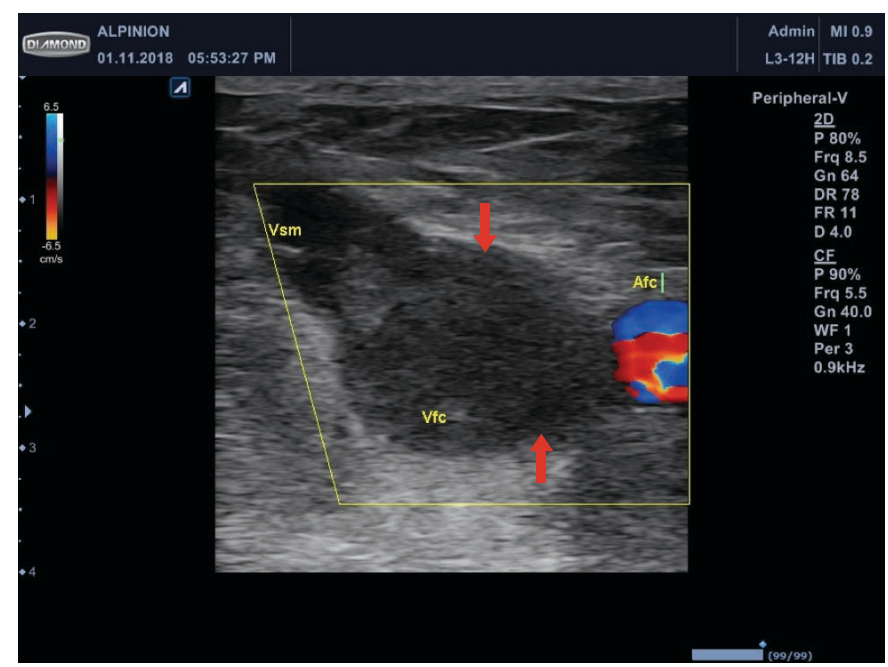

FIGURE 1. Venous Doppler ultrasound revealed a bulky intraluminal, partially occlusive thrombus in the right common femoral vein (arrow)
Venous Doppler ultrasound of the lower limbs discovered extensive bilateral DVT, with an occlusive thrombus in the right common femoral vein, right popliteal and calf veins, associated with occlusive thrombosis in the left common femoral vein, left femoral vein, left popliteal and left calf veins, and lymph nodes up to $17 / 7 \mathrm{~mm}$ in size in the right inguinal area (Figures 1-3).

Computed tomography (CT) scanning with intravenous contrast showed bilateral pulmonary emboli, larger in the right pulmonary artery, extending to the level of the upper and lower branches and emboli in the inferior branch of the right pulmonary artery (Figure 4).

The patient was diagnosed with AOSD 7 months prior and was initially under treatment with non-steroidal antiinflammatory drugs (NSAIDs). Because his symptomatology did not response to NSAIDs, he received prednisolone and methotrexate. At the time of the AOSD diagnosis, our patient fulfilled 2 major and 4 minor criteria of diagnosis

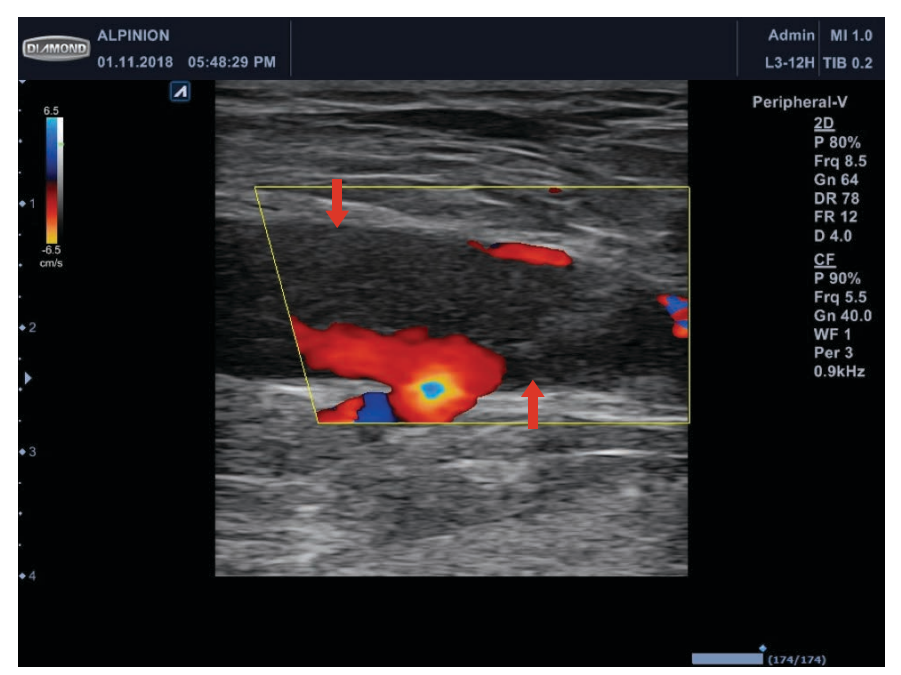

FIGURE 2. Venous Doppler ultrasound revealing intraluminal thrombus with marginal flow (arrow) 


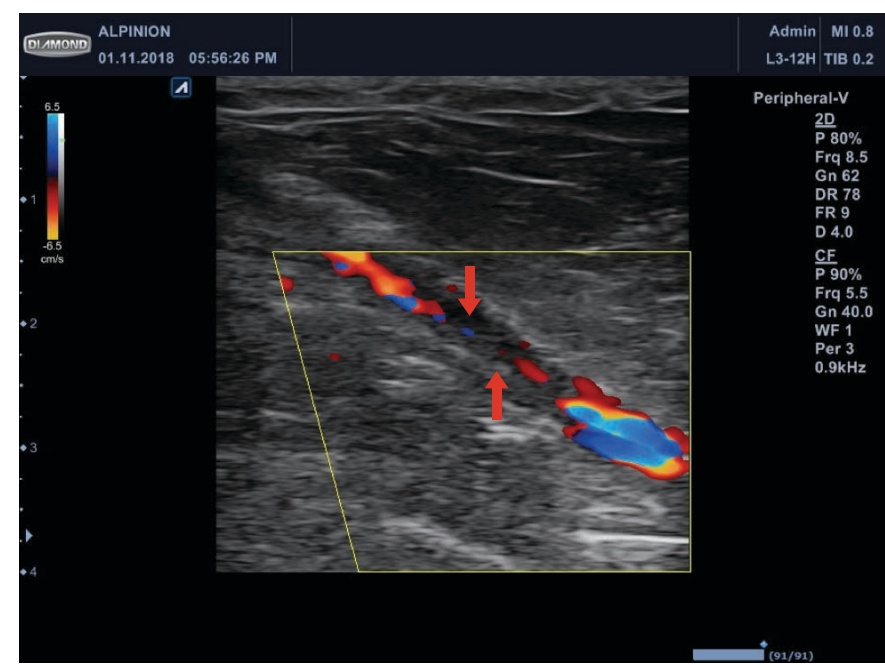

FIGURE 3. Venous Doppler ultrasound revealing a partially occlusive thrombus with marginal flow (arrow)

according to Yamaguchi's list (Table 2). At presentation, the patient was under treatment with prednisolone and methotrexate, and the symptomatology of AOSD was partially improved.

In order to improve survival and to prevent complications, the patient was instructed to wear venous compression stockings and anticoagulant therapy was initiated with low-molecular weight heparin and oral rivaroxaban.

The evolution of the patient was favorable, and he was discharged after several days, with significant improve-

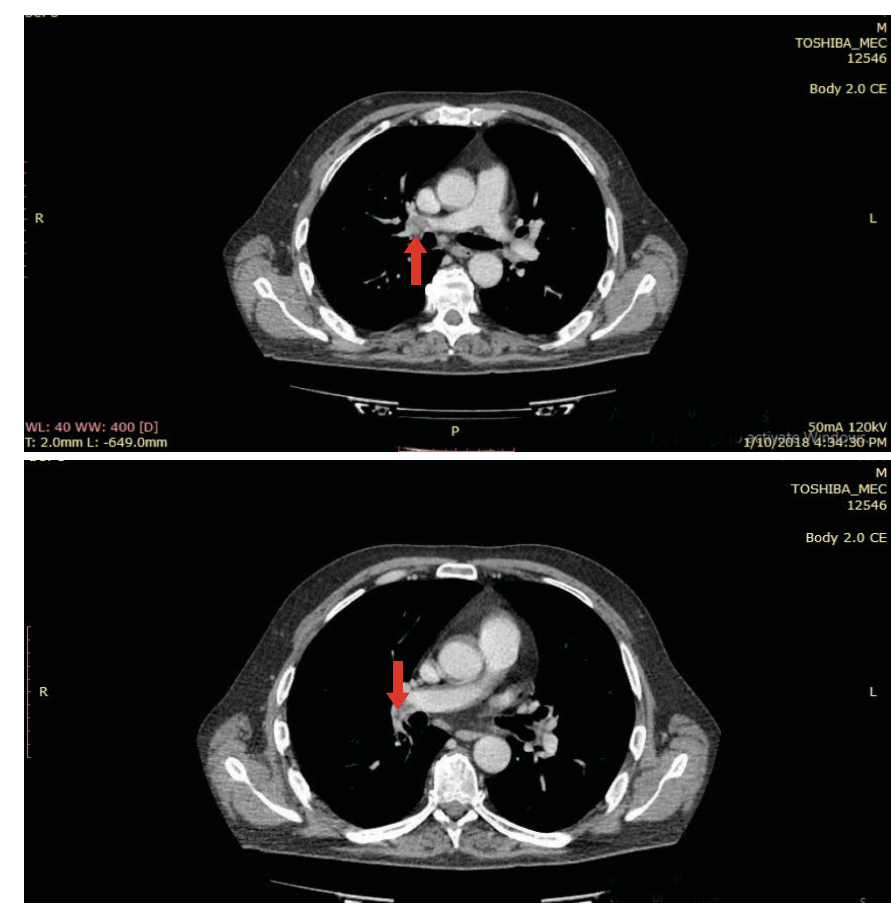

FIGURE 4. Computed tomography angiography revealing pulmonary arterial emboli in the right pulmonary artery (arrows)

ment of his clinical signs and symptoms, without developing any bleeding complications.

The presentation of this case was approved by the Ethics Committee of the hospital and written informed consent was obtained from the patient.

TABLE 2. Yamaguchi criteria in the patient with AOSD

\begin{tabular}{|c|c|c|}
\hline & Present & Absent \\
\hline \multicolumn{3}{|l|}{ MAJOR CRITERIA } \\
\hline Fever $>39^{\circ} \mathrm{C}$, lasting 1 week or longer & & $\mathrm{X}$ \\
\hline Arthralgia or arthritis, lasting 2 weeks or longer & $\mathrm{X}$ & \\
\hline Typical salmon-colored rash & & $\mathrm{X}$ \\
\hline Leukocytosis $>10.000 / \mathrm{mm}^{3}$ with $>80$ polymorphonuclear cells & $\mathrm{X}$ & \\
\hline \multicolumn{3}{|l|}{ MINOR CRITERIA } \\
\hline Sore throat & & $\mathrm{X}$ \\
\hline Recent development of significant lymphadenopathy & $\mathrm{X}$ & \\
\hline Hepatomegaly or splenomegaly & $\mathrm{X}$ & \\
\hline Abnormal liver function tests & $\mathrm{X}$ & \\
\hline $\begin{array}{l}\text { Negative tests for antinuclear antibody (IF) and rheumatoid } \\
\text { factor (IgM) }\end{array}$ & $\mathrm{X}$ & \\
\hline \multicolumn{3}{|l|}{ EXCLUSION CRITERIA } \\
\hline Infections & & $\mathrm{X}$ \\
\hline Malignancies (malignant lymphoma) & & $\mathrm{X}$ \\
\hline Other rheumatic disease (systemic vasculitides)\} $&{ } &{\mathrm{X}} \\
$\hline
\end{tabular}




\section{DISCUSSIONS}

Venous thromboembolism involves both deep vein thrombosis and pulmonary embolism and is an extremely serious condition, with an estimated occurrence of approximately 1 in 1.000 adults annually. ${ }^{12}$ The potential risk factors for this devastating disease are numerous: malignancy, different types of trauma, protein C or S deficiency. ${ }^{13}$

Important epidemiologic data on AOSD are missing. AOSD affects predominantly young adults, although it can also be present among geriatric patients. ${ }^{14-17}$ Cagatay et al. demonstrated that women seem to be more affected than men by this rare disease..$^{18}$ The mechanisms underlying AOSD are not fully known to date; however, different studies have been published suggesting a role of genetic, infectious and environmental factors in the physiopathology of this syndrome. ${ }^{19}$

The diagnosis of AOSD is based on Yamaguchi's criteria (1992), which were associated with a sensitivity of 93.5\% for diagnosing this disease. ${ }^{20}$ These criteria include 4 major criteria (fever above $39^{\circ} \mathrm{C}$ lasting one week or longer, arthralgia or arthritis lasting 2 weeks or longer, typical rash and leukocytosis above $10,000 / \mathrm{mm}^{3}$ ) and 5 minor criteria (sore throat, recent development of significant lymphadenopathy, hepatomegaly or splenomegaly, abnormal liver function tests, and negative tests for antinuclear antibody and rheumatoid factor). ${ }^{7}$ Our patient fulfilled 2 major and 4 minor criteria when he was first diagnosed with AOSD.

Other features representative for this disease are myalgia, lymphadenopathy, pleurisy, pericarditis, weight loss, and involvement of the central nervous system. ${ }^{6}$ In most cases of AOSD (more than $70 \%$ of the patients), laboratory findings show elevation of the erythrocyte sedimentation rate, leukocytosis, and elevated ferritin levels, as seen in our patient. ${ }^{18,21}$ However, other diagnoses such as rheumatic diseases (mainly systemic vasculitis), infections and malignancies (mainly malignant lymphoma) should be excluded before establishing the final diagnosis of AOSD. ${ }^{20}$

Two distinct AOSD phenotypes can be differentiated in the general population: the first type is exceedingly symptomatic, characterized by fever, which could develop into a systemic pattern (mono- or polycyclic); the second type is characterized by arthritis as the main symptom and poor systemic symptomatology, developing a chronic articular pattern. ${ }^{22,23}$

In clinical practice, it is very important to recognize the clinical and laboratory characteristics of AOSD, an uncommon disorder with multiple non-specific signs and symptoms, as it may generate different medical complications.
The association between AOSD and pulmonary embolism is rare, but several studies addressed this interesting correlation. In a retrospective study, Al-Temimi et al. collected data from 6 patients diagnosed with AOSD, highlighting the demographic and clinical features associated with this disease, and found that one of the 6 patients had a pulmonary embolism which led to death. ${ }^{24}$ Also, a study by Merashli et al. identified venous thromboembolism as an initial manifestation of AOSD. ${ }^{25}$

According to other cases from the literature, venous thromboembolism occurs extremely rarely in AOSD, and this is possible due to enhanced coagulation activation. ${ }^{26}$ Coagulation activation in AOSD can induce disseminated intravascular coagulation with multi-organ failure and also digital autoamputation. ${ }^{27}$ According to several authors, NSAIDs or prednisolone and methotrexate could be recommended for subjects not responding to NSAIDs. ${ }^{28,29}$

\section{CONCLUSIONS}

AOSD has several manifestations which can limit life expectancy. Venous thromboembolism, as a presentation of AOSD, is exceedingly rare, but life-threatening.

In our opinion, a careful consideration of the association between AOSD and coagulation imbalance should be further investigated in order to prevent the risk of massive and fatal thrombotic events in patients with AOSD.

\section{CONFLICT OF INTEREST}

Nothing to declare.

\section{REFERENCES}

1. Gerfaud-Valentin M, Maucort-Boulch D, Hot A, et al. Adultonset Still disease: manifestations, treatments, outcome, and prognostic factors in 57 patients. Medicine (Baltimore). 2014;93:91-99. doi: 10.1097/MD.0000000000000021.

2. Magadur-Joly G, Billaud E, Barrier JH, et al. Epidemiology of adult Still's disease: estimate of the incidence by a retrospective study in west France. Ann Rheum Dis. 1995;54:587-590.

3. Still G. On a Form of Chronic Joint Disease in Childhood. Med Chir Trans. 1897;88:47-49.

4. Sunderkotter C, Frieling U, NashanD, Metze D. Adult Onset Still's Disease and its Characteristic Rash. Hautarzt. 1988;49:920-924.

5. Larson EB. Adult Still's disease-recognition of a clinical syndrome and recent experience. West J Med. 1985;142:665671.

6. Cush JJ, Medsger TA Jr, Christy WC, Herbert DC, Cooperstein LA. Adult-onset Still's disease. Clinical course and outcome. Arthritis Rheum. 1987;30:186-194. 10.1002/art.1780300209. 
7. Yamaguchi M, Ohta A, Tsunematsu T, et al. Preliminary criteria for classification of adult Still's disease. J Rheumato. 1992;19;424-430.

8. Horlander KT, Mannino DM, Leeper KV. Pulmonary embolism mortality in the United States, 1979-1998: an analysis using multiple-cause mortality data. Arch Intern Med. 2003;163:1711-1717. doi: 10.1001/archinte.163.14.1711.

9. Tapson VF. Acute pulmonary embolism. N Engl J Med. 2008;358:1037-1052. doi: 10.1056/NEJMra072753.

10. Duketis JD, Kearon C, Bates S, Duku EK, Ginsberg JS. Risk of fatal pulmonary embolism in patients with treated venous thromboembolism. JAMA. 1998;279:458-462.

11. Pouchot J, Sampalis JS, Carette S, etal. Adult Still's Disease: Manifestations, disease course, and outcome in 62 patients. Med. 1991;70:118-136.

12. Cushman M. Epidemiology and risk factors for venous thrombosis. Semin Hematol. 2007;44:62-69.

13. Wolfe TR, Allen TL. Syncope as an emergency department presentation of pulmonary embolism. J Emerg Med. 1998;16:27-31. doi: 10.1016/S0736-4679(97)00228-X.

14. Crispin JC, Martinez-Banos D, Alcocer-Varela J. Adult-onset Still disease as the cause of fever of unknown origin. Medicine (Baltimore). 2005;84:331-337.

15. Mert A, Ozaras R, Tabak F, et al. Fever of unknown origin: a review of 20 patients with adult-onset still's disease. Clin Rheumatol. 2003;22:89-93. doi: 10.1007/s10067-002-0680-3.

16. Pouchot J, Sampalis JS, Beaudet F, et al. Adult Still's disease: manifestations, disease course and outcome in 62 patients. Medicine (Baltimore). 1991;70:118-136.

17. Steffe LA, Cooke CL. Still's disease in a 70-year-old woman. JAMA. 1983;249:2062-2063.

18. Cagatay Y, Gul A, Cagatay A, et al. Adult-onset Still's disease. Int J Clin Pract. 2009;63:1050-1055.
19. Fautrel B. Adult-onset Still disease. Best Pract Res Clin Rheumatol. 2008;22:773-792. doi: 10.1016/j.berh.2008.08.006.

20. Masson C, Le Loet X, Liote F, et al. Comparative study of 6 types of criteria in adult Still's disease. J Rheumatol. 1996;23:495-497.

21. Kelly J, Chowienczyk P, Gibson T. Sore throat and hyperferritinaemia. J R Soc Med. 2001;94:400-401.

22. Cush JJ, Medsger Jr TA, Christy WC, Herbert DC, Cooperstein LA. Adult-onset Still's disease. Clinical course and outcome. Arthritis Rheum. 1987;30:186-194.

23. Wouters JM, van de Putte LB. Adult-onset Still's disease; clinical and laboratory features, treatment and progress of 45 cases. OJM. 1986;61:1055-1065.

24. Al-Temimi FA, George P. Adult onset Still's disease in Oman. Sultan Qaboos Univ Med J. 2006;6:41-45.

25. Merashli M, Jawad A, Ames PRJ. Venous thromboembolism as initial manifestation of adult onset Still's disease. Scand J Rheumatol. 2015;44:4:340-341. doi: 10.3109/03009742.2015.1021377.

26. Gallistl S, Mangge H, Neuwirth G, Muntean W. Activation of the haemostatic system in children with juvenile rheumatoid arthritis correlates with disease activity. Thromb Res. 1998;92:267-272.

27. Ames PRJ, Walker E, Aw D, Marshall D, de Villiers F, Staber M. Multi-organ failure in adult onset Still's disease: a septic disguise. Clin Rheumatol. 2009;28:S3-S6. doi: 10.1007/ s10067-008-1010-1.

28. Kadar J, Petrovicz E. Adult-onset Still's disease. Best Pract Res Clin Rheumatol. 2004;18:663-676.10.1016/j.berh.2004.04.004.

29. Aydintung AO, D, Cruz D, Cervera R, Khamashta MA, Hughes GR. Low dose methotrexate treatment in adult Still's disease. J Rheumatol. 1992;19:431-435. 